RESEARCH ARTICLE

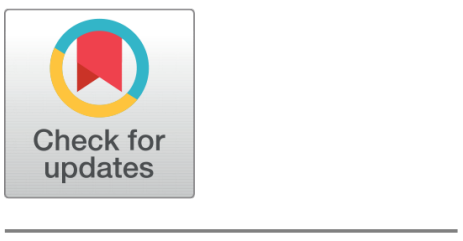

OPEN ACCESS

Received: 07.05.2021

Accepted: 05.10.2021

Published: 25.10 .2021

Citation: Asri ARH, Prasetyo A, Sadhana U, Antari AL, Rahajeng $\mathrm{H}$ (2021) Trend Analysis of Superoxide Dismutase 3 (SOD3) and Reactive Oxygen Species (ROS) levels on BioSmart and Safe Bus Passengers. Indian Journal of Science and Technology 14(34): 2751-2760. https ://doi.org/10.17485/IJST/v14i34.769

* Corresponding author.

lodadi54@yahoo.co.id

Funding: None

Competing Interests: None

Copyright: (c) 2021 Asri et al. This is an open access article distributed under the terms of the Creative Commons Attribution License, which permits unrestricted use, distribution, and reproduction in any medium, provided the original author and source are credited.

Published By Indian Society for Education and Environment (iSee)

ISSN

Print: 0974-6846

Electronic: 0974-5645

\section{Trend Analysis of Superoxide Dismutase 3 (SOD3) and Reactive Oxygen Species (ROS) levels on BioSmart and Safe Bus Passengers}

\author{
A R Hairul Asri ${ }^{*}$, Awal Prasetyo², Udadi Sadhana ${ }^{3}$, \\ Arlita Leniseptaria Antari ${ }^{4}$, Hehera Rahajeng ${ }^{1}$
}

1 Postgraduate Student, Masters in Biomedical Sciences, Faculty of Medicine, Diponegoro University, Semarang, Indonesia

2 Lecturer, Department of Biomedical Science, Faculty of Medicine, Diponegoro University, Semarang, Indonesia

3 Lecturer, Department of Pathology Anatomy, Faculty of Medicine, Diponegoro University, Semarang, Indonesia

4 Lecturer, Department of Microbiology, Faculty of Medicine, Diponegoro University,

Semarang, Indonesia

\section{Abstract}

Objective: To assess the effect of the Biosmart and safe concept on the levels of superoxide Dismutase 3 (SOD3) and reactive oxygen species (ROS) in the bus passenger nasal wash. Methods: This study is a non-blinding experimental design with a pretest-posttest measurement. The number of participants was 31 passengers of Biosmart and Safe Bus; divided into 2 groups: herbal masks and regular medical masks. Participants were divided into front, middle, and rear seat positions. Findings: The trend of SOD3 and ROS levels in the herbal mask group was increasing, while the trend in the medical mask group was decreasing. There was a significant difference in SOD3 levels in the middle seat position $(p=0.037)$ and ROS levels in the rear seat position $(p=0.022)$. There was a strong negative relationship between SOD3 levels and ROS levels in the herbal mask group $(p=0.016, r=-0.611)$. There was a significant difference in the levels of ROS on pretest-posttest of the medical mask group $(p=0.039)$, and the ROS levels in the herbal mask group approached a significant value ( $p$ $=0.059$ ). There was no significant difference in SOD3 and ROS levels between the herbal mask and medical mask groups $(p=0.937 ; 0.810)$. Novelty : The ROS levels of Biosmart and Safe Bus passengers who use Herbal Masks are different from those using regular medical masks with lower levels. The SOD3 levels of Biosmart and Safe bus passengers who use herbal masks are different from those who use higher levels of regular medical masks.

Keywords: Biosmart and Safe Bus; herbal mask; nasal wash; ROS; SOD3 


\section{Introduction}

Respiratory tract infectious diseases are at risk of being transmitted through public transportation such as buses, planes, and trains. This risk increases the frequency of passengers using public transportation /buses. ${ }^{(1)}$ The use of the ventilation system affects infectious airborne particles in the confined spaces such as the cabin of vehicles, ex: cars and buses. Air change speed in the cabin for about 5 to $12 \mathrm{ACH}$ (air change/hour) can reduce the risk of exposure but does not eliminate infectious airborne particles. ${ }^{(2)}$ In addition, exposure to pollutant compounds in the bus cabin increases the health risk of passengers. Among the pollutant compounds that affect the health of passengers, the most are PM2.5 by $25 \%$ and CO which has a concentration of $50 \%$ of the pollutant compounds on the roadway. ${ }^{(3)}$

When infectious airborne particles and pollutants are inhaled, these particles can penetrate the respiratory epithelial cells present in the nose. This condition disrupts cell function by forming reactive oxygen species (ROS) which disrupts the balance of oxidants and antioxidants and results in oxidative stress. This condition is exacerbated if the infectious airborne particles that penetrated can inhibit the activity of antioxidant enzymes such as SOD3 by decreasing the number of transcription factors such as Nrf-2 (Nuclear transcription factor NFE2-related factor2). ${ }^{(4)}$

Nowadays, public transportation has been developed by using the BioSmart and Safe Bus concepts to adopt the new habits during the pandemic. The bus that applies the Bio Smart concept has been carried out by adjusting the seat distance between passengers which aims to maintain distance (Physical Distancing), by forming a laminar / more vertical airflow as air circulation system regulation, using HEPA (high-efficiency particle air filter) Filter technology, UV-C (ultraviolet-C) lamps and Nano silver technology on the entire surface of the bus cabin. The Safe concept was carried out by the use of a mask for every passenger to increase safety from the risk of being exposed to infectious particles and pollutants. ${ }^{(5)}$ Setiyo M. et al. (2020) reported about the smart solution for physical distancing on buses during COVID-19 pandemic, while Dzisi EKJ et al. (2020) reported the social distancing and the use of mask in public transportation during COVID-19 pandemic. ${ }^{(6,7)}$

The use of masks has become a new habit for people to prevent from contracting diseases such as Covid-19. The effectiveness of masks used to protect the respiratory tract from viruses and pollution depends on several factors, including the density of the filament, the suitability of the mask with facial anatomical contours, facial movement when using a mask, and the airflow level that passes through the mask and mask material. ${ }^{(8)}$

Currently, mask materials that use herbal ingredients are rarely being researched and developed. Moreover, several masks with herbal plant material have been developed. The herbal mask was made from a combination of the herbal plants Nephrolepis exaltata and Hibiscus rosa sinensis (NEHRS). The previous research on herbal masks has shown the ability of these herbal masks to improve nasal mucociliary transport, increase sinonasal IgA antibody levels, and improve pulmonary function in textile factory employees. ${ }^{(9)}$ In addition, herbal masks have the potential to prevent the free radicals from damaging cells and strengthen endogenous antioxidant activity such as the Superoxidase dismutase (SOD) enzyme, due to antioxidants and antiinflammatory compounds they were contained of. ${ }^{(10,11)}$ However, the effectiveness of this herbal mask has never been tested in public bus transportation, which has a high risk of exposure to both infectious airborne particles and toxic air pollution compounds.

This study aims to analyze the cellular response with the balance between oxidant (ROS) and antioxidants (SOD3) as a marker of oxidative stress in public transportation passengers on buses using the Biosmart and Safe bus concepts.

\section{Materials and Methods}

This study was a non-blinding randomization experimental design with a pretest-posttest measurement. This study followed the CONSORT (consolidated standards of reporting trial) guideline. Participants were "Biosmart and Safe Bus" passengers with the inclusion criteria: aged 15-64 years, agreed to participate in the study (written informed consent), were in good health, and had a negative result of Covid-19 antibody rapid screening test. The exclusion criteria: having a history of chronic lung disease, heart disease, and allergies, are pregnant, or with a history of hereditary diseases. The sample size determination based on number of passengers who frequently use the bus. The allocation of group was done using simple randomization. In total, the number of participants was 31 people based on the inclusion criteria who were randomly divided into 2 groups (simple randomization): the herbal mask treatment group $(n=15)$ and the regular medical mask control group $(n=16)$ (with the time duration of the use of mask was the participant's travel time). Participants were traveled by Biosmart and Safe Bus for a minimum of 6 hours. [1] Participants were taken pre-test samples with the Nasal Wash method. After that, the post-test sampling was carried out in the same way as the pre-test method (Figure 1). 


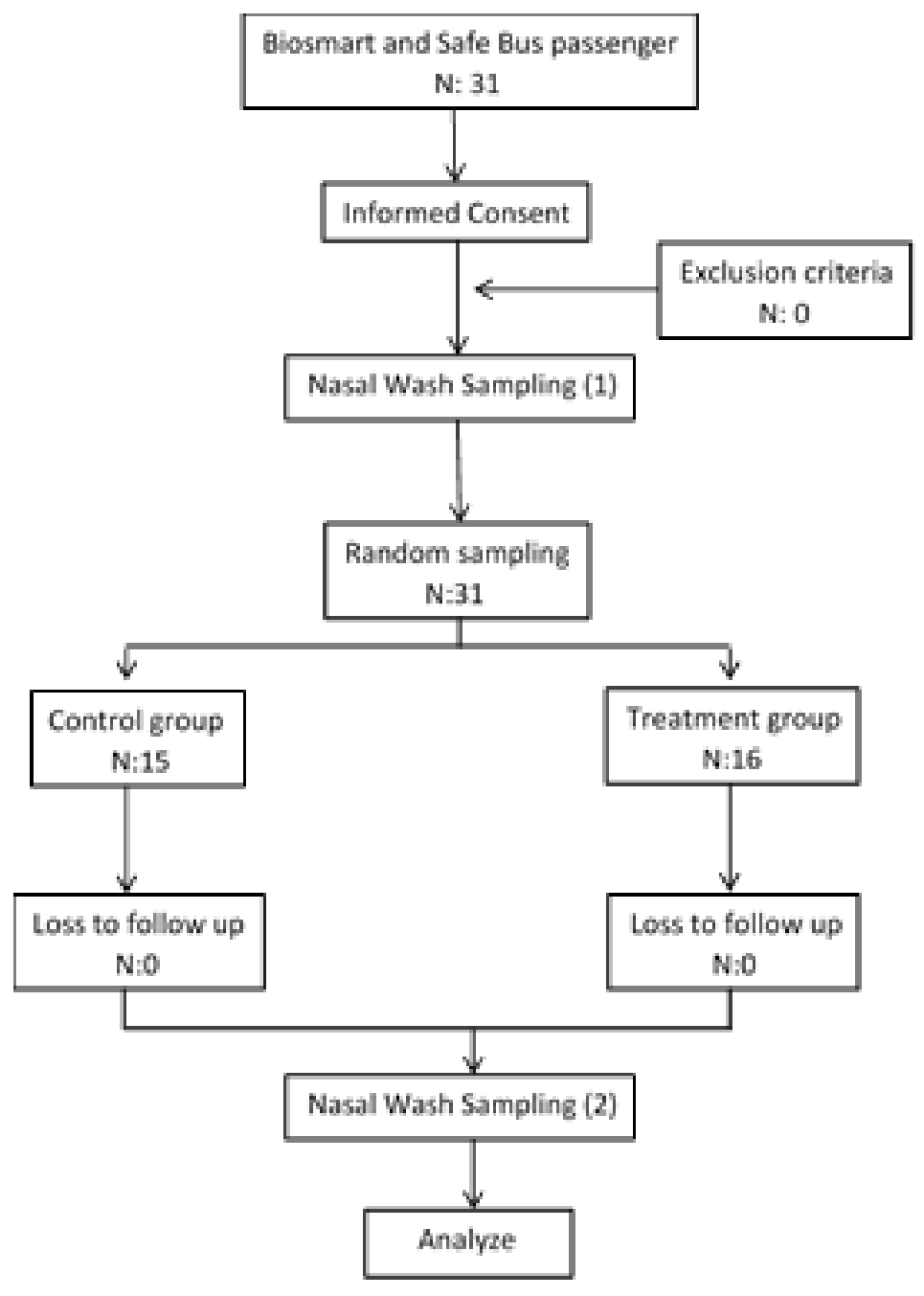

Fig 1. Study design

\subsection{Preparation of NEHRS Herbal masks}

The NEHRS herbal mask extract was made in the Applied Science Dept. laboratory of Diponegoro University. The mask product has received a patent with registration number No. S00201909409. The NEHRS herbal mask produced by CV. Kasatama Surabaya.

\subsection{Preparation of Biosmart and Safe Bus}

The process of making the bus prototype was done by making a 1-1-1 seat configuration. The use of the air control system on the bus was performed by applying HEPA Filters, UV-C lamps, and Nanosilver coatings on the entire surface of the bus cabin. The entire process was carried out by CV. Karoseri Laksana, Semarang.

\subsection{Laboratory Analysis}

Analyze of SOD-3 and ROS levels was obtained from a nasal wash sample (immediately before and after the trip). The sampling process was carried out by instructing the respondent to sit with a $45^{\circ}$ extension of the head. Participants were asked to take a deep breath and then hold it. A total of $10 \mathrm{cc}$ of aquabidest at $37^{\circ} \mathrm{C}$ is injected into the left and right nasal cavity. Participants maintain their position for a moment and then the samples are collected into a container. Nasal wash samples were stored at $4^{\circ} \mathrm{C}$ for later examination by the ELISA method. ELISA examination for SOD3 and ROS levels used Human Reactive Oxygen 
Species (ROS) ELISA Kit 96 wells SUNLONG BIOTECH SL2046Hu and Human Superoxide Dismutase 3, Extracellular ELISA Kit (SOD3) 96 wells ABCLONAL RK02313- 96wells.

\subsection{Statistic analysis}

All data was analyzed by using SPSS version 25. The data distribution of SOD3 and ROS was tested with Shapiro Wilk method. Primary data of SOD3 and ROS were analyzed using Mann- Whitney, wilcoxon, kruskal wallis, one way anova, paired T, and independent $\mathrm{T}$ test based on the type of group. Pearson correlation test was used for the correlation of data. The trend analysis was assessed by making a mathematical trend formula for delta/difference in SOD3 and ROS levels to see the trend in the direction of the graph.

\subsection{Ethical Clearence}

The study had received approval from the Ethics Commission of the Faculty of Medicine and RSUP Dr.Kariadi with number 240 / EC / KEPK / FK-UNDIP / X / 2020

\section{Results}

\subsection{Participants Characteristics}

Figure 2 showed CONSORT flow diagram of reporting this study. The analysis of participant's characteristics was assessed based on gender, age, body mass index (BMI), seating position, and smoking history. All results showed insignificant values $(\mathrm{p}>0.05)$ both in treatment and control groups (Table 1 , successful randomization).

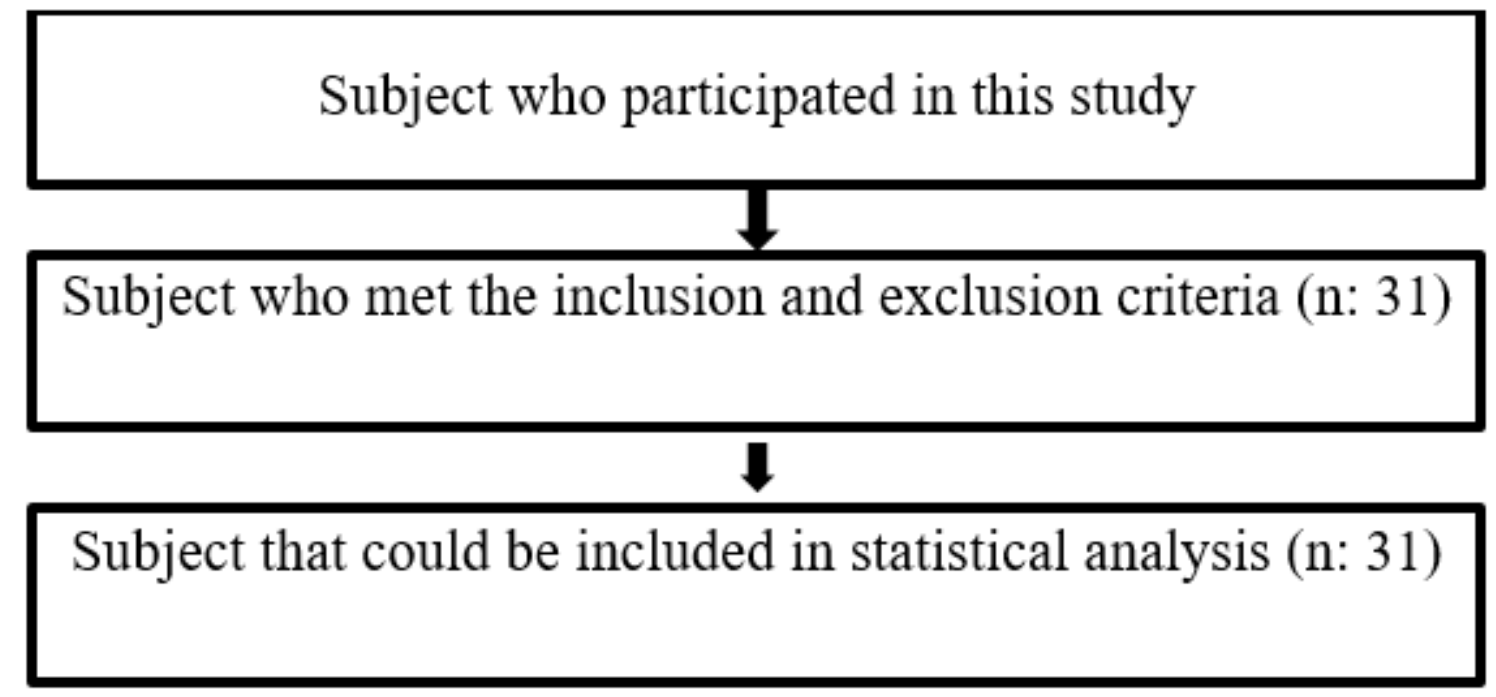

Fig 2. CONSORT flow diagram 
Table 1. Demographic and data of the participants based on group

\begin{tabular}{|c|c|c|c|c|c|c|c|}
\hline \multirow{3}{*}{ Variable } & \multicolumn{6}{|c|}{ Mask Type } & \multirow{3}{*}{$\mathrm{P}$} \\
\hline & \multicolumn{3}{|c|}{ Herbal } & \multicolumn{3}{|c|}{ Medical } & \\
\hline & $\mathrm{N}$ & $\%$ & Mean & $\mathrm{N}$ & $\%$ & Mean & \\
\hline Gender & & & & & & & 1,000 \\
\hline Male & 13 & 86,7 & & 13 & 81,3 & & \\
\hline Female & 2 & 13,3 & & 3 & 18,8 & & \\
\hline Smoking history & & & & & & & 0,208 \\
\hline Yes & 7 & 46,7 & & 4 & 25 & & \\
\hline No & 8 & 53,3 & & 12 & 75 & & \\
\hline BMI & & & & & & & 0,822 \\
\hline Underweight & 1 & 6,7 & & 1 & 6,3 & & \\
\hline Normal & 5 & 33,3 & & 7 & 43,8 & & \\
\hline Overweight & 5 & 33,3 & & 3 & 18,8 & & \\
\hline Obese & 4 & 26,7 & & 5 & 31,3 & & \\
\hline Seating position & & & & & & & 0,521 \\
\hline Front & 7 & 46,7 & & 6 & 31,3 & & \\
\hline Middle & 3 & 20 & & 6 & 37,5 & & \\
\hline Rear & 5 & 33,3 & & 5 & 31,3 & & \\
\hline Age & & & $32,07=$ & & & $26,88 \pm 9,54$ & 0,235 \\
\hline
\end{tabular}

\subsection{SOD3 and ROS levels}

From the results obtained, seen in (Figure 3), that the trend of SOD3 levels in the treatment group (herbal mask) tends to increase, so is the trend of SOD3 levels in the control group (medical mask) which tends to increase (Figure 4). The trend of ROS levels in the treatment group (herbal mask) tends to increase (Figure 5) hence the trend of ROS levels in the control group were tends to decrease (Figure 6). Based on (Table 2), there was no significant difference between the increase of SOD3 levels after treatment in the herbal mask group $\mathrm{p}=0.865(\mathrm{p}<0.05)$ and the decrease of SOD3 levels in the medical mask group $\mathrm{p}=$ 0.642 ( $\mathrm{p}<0.05)$. The difference of SOD3 levels in the two groups showed no significant results. There was a significant difference in SOD3 levels after boarding the bus with a middle seating position with $\mathrm{p}=0.037(\mathrm{p}<0.05)$ (Table 3$)$. The ROS levels in the medical mask group showed a significant increase after treatment with a $\mathrm{p}$-value $=0.037(\mathrm{p}<0.05)($ Table 4$)$. While the increase in ROS levels in the herbal mask group after treatment was not significant $p=0.059(\mathrm{p}<0.05)$. As shown from (Table 5), there was a significant difference in the increase in ROS levels after boarding the bus with the rear seating position with a value of $\mathrm{p}$ $=0.022(\mathrm{p}<0.05)$.

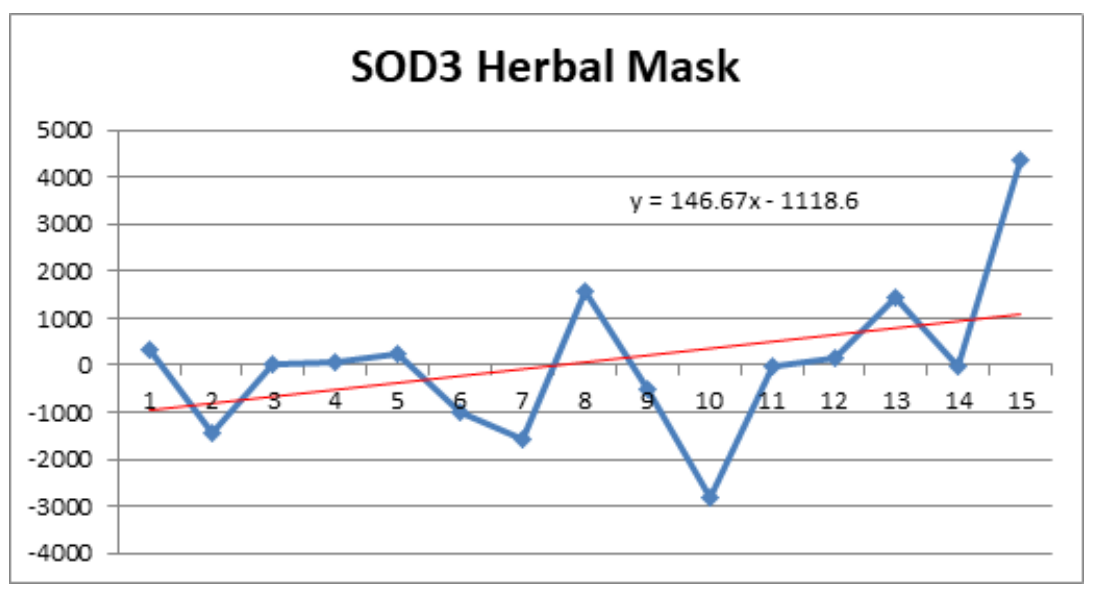

Fig 3. Trends of Delta SOD3 levels on herbal mask group graphic 


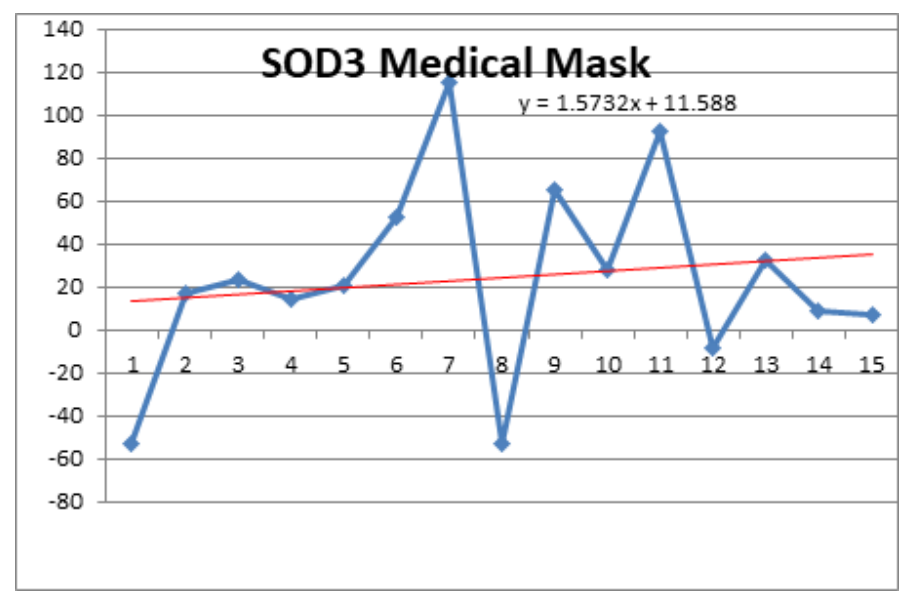

Fig 4. Trends of Delta SOD3 levels on medical mask group graphic

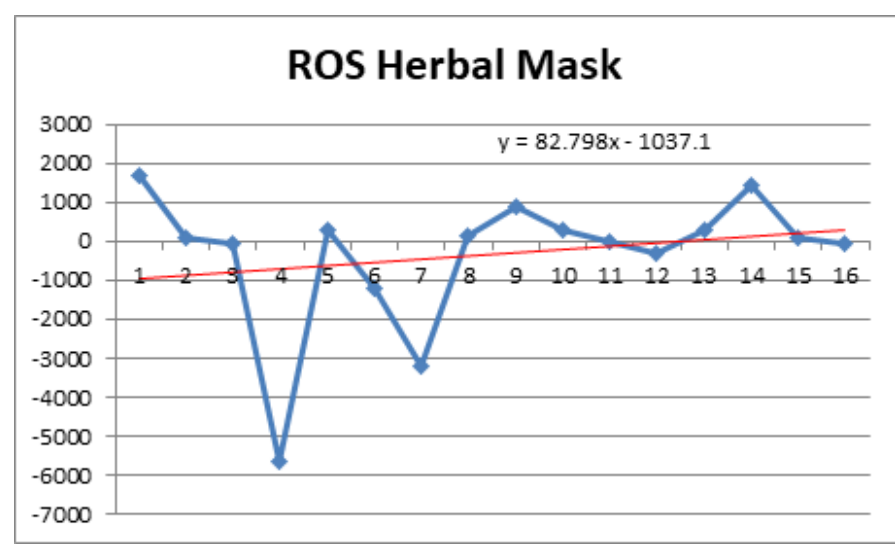

Fig 5. Trends of Delta ROS levels on herbal mask group graphic

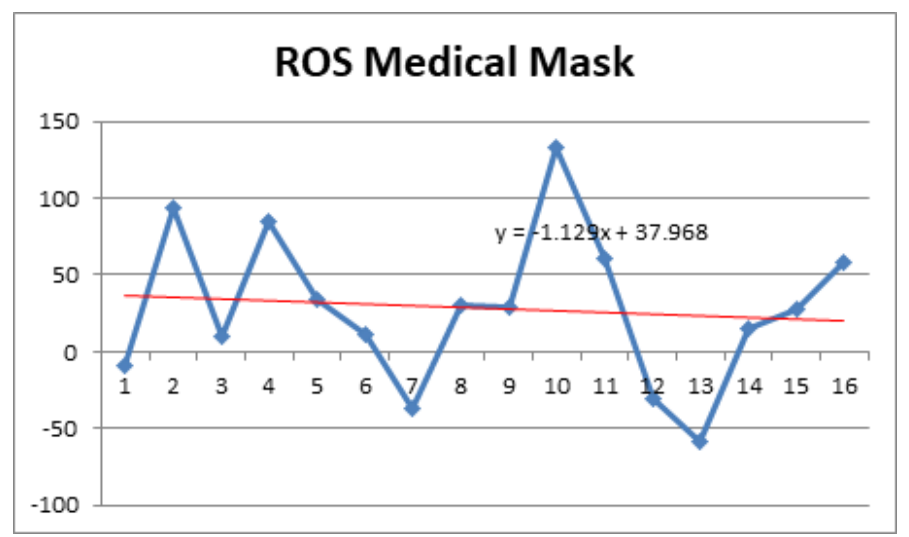

Fig 6. Trends of Delta ROS levels on medical mask group graphic 
Table 2. The difference of SOD3 levels on pre test, post test and delta

\begin{tabular}{llll}
\hline \multirow{2}{*}{ SOD3 } & Mask Type & & $\mathrm{p}$ \\
\cline { 2 - 3 } & Herbal & Medical & $0,693^{\ddagger}$ \\
\hline Pre test & $752,18 \pm 855,48$ & $1006,66 \pm 1902,17$ & $0,843^{\ddagger}$ \\
Post test & $806,87 \pm 1233,18$ & $673,33 \pm 637,00$ & $0,937^{\ddagger}$ \\
$\mathrm{p}$ & $0,865^{\dagger}$ & $0,642^{\dagger}$ & $-333,33 \pm 1793,54$ \\
Delta & $54,69 \pm 1634,91$ & & \\
\hline
\end{tabular}

Note : ${ }^{*}$ Significant $(\mathrm{p}<0,05) ;{ }^{\ddagger}$ Mann whitney; ${ }^{\dagger}$ Wilcoxon

Table 3. The difference of SOD3 levels on pre test, post test and delta based on seating position

\begin{tabular}{lllll}
\hline \multirow{2}{*}{ Seating Position } & SOD3 & Post test & $\mathrm{p}$ & Delta \\
\cline { 2 - 4 } & Pre test & $960,42 \pm 860,12$ & $0,814^{\dagger}$ & $-851,34 \pm 2811,29$ \\
\hline Front & $1811,76-3071,57$ & $693,48 \pm 568,53$ & $0,037^{\Im *}$ & $470,52 \pm 571,23$ \\
Middle & $222,65 \pm 198,77$ & $362,07 \pm 391,18$ & $0,064^{\Im}$ & $-779,93 \pm 1482,46$ \\
Rear & $1142,00 \pm 1526,47$ & $0,543^{\S}$ & & $0,496^{\S}$ \\
p & $0,219^{\ddagger}$ & 0,541 & 0,509 \\
Levene & & & 0 \\
\hline
\end{tabular}

Note : ${ }^{\star}$ Significant $(\mathrm{p}<0,05) ;{ }^{*}$ Kruskal Wallis; ${ }^{\S}$ One Way Anova; ${ }^{\dagger}$ Wilcoxon; ${ }^{9}$ Paired t

Table 4. The difference of ROS levels onpre test, post test and delta

\begin{tabular}{|c|c|c|c|}
\hline \multirow{2}{*}{ ROS } & \multicolumn{2}{|l|}{ Mask Type } & \multirow{2}{*}{$\mathrm{p}$} \\
\hline & Herbal & Medical & \\
\hline Pre test & $98,64 \pm 35,10$ & $113,28 \pm 38,25$ & $0,277^{\S}$ \\
\hline Post test & $122,82 \pm 24,12$ & $141,66 \pm 37,14$ & $0,107^{\S}$ \\
\hline $\mathrm{p}$ & $0,059^{9}$ & $0,039^{9} *$ & \\
\hline Delta & $24,17 \pm 45,62$ & $28,37 \pm 50,26$ & $0,810^{\S}$ \\
\hline
\end{tabular}

Note: ${ }^{\star}$ Significant $(\mathrm{p}<0,05) ;{ }^{\S}$ Independent $\mathrm{t} ;{ }^{9}$ Paired $\mathrm{t}$

Table 5. The difference of ROS levels on pre test, post test and delta based on seating position

\begin{tabular}{|c|c|c|c|c|}
\hline \multirow{2}{*}{ Seating Position } & \multicolumn{2}{|l|}{ ROS } & \multirow[b]{2}{*}{$\mathrm{p}$} & \multirow{2}{*}{ Delta } \\
\hline & Pre test & Post test & & \\
\hline Front & $111,45 \pm 33,00$ & $123,06 \pm 28,16$ & $0,367^{9}$ & $11,61 \pm 42,80$ \\
\hline Middle & $121,94 \pm 41,74$ & $150,07 \pm 30,34$ & $0,134^{9}$ & $28,14 \pm 50,67$ \\
\hline Rear & $85,74 \pm 30,16$ & $128,14 \pm 35,67$ & $0,022^{9 *}$ & $42,40 \pm 48,61$ \\
\hline $\mathrm{p}$ & $0,535^{\S}$ & $0,909^{\S}$ & & $0,819^{\S}$ \\
\hline Levene & 0,743 & 0,887 & & 0,895 \\
\hline
\end{tabular}

Note : ${ }^{*}$ Significant $(\mathrm{p}<0,05) ;{ }^{\S}$ One Way Anova; ${ }^{9}$ Paired $\mathrm{t}$

\subsection{Correlation of SOD-3 levels with ROS levels}

From (Table 6), the Pearson test results showed that in the herbal mask group there was a significant relationship between SOD3 and ROS levels with a strong negative category with a value of $\mathrm{p}=0.016(\mathrm{p}<0.05)$ and $\mathrm{r}=-0.611$.

Table 6. Correlation test result of delta SOD 3 to delta ROS

\begin{tabular}{lllllll}
\hline \multirow{2}{*}{ Delta } & Herbal Mask & \multicolumn{5}{c}{ Medical Mask } \\
\cline { 2 - 7 } & Mean \pm SD & $\mathrm{p}$ & $\mathrm{r}$ & Mean \pm SD & $\mathrm{p}$ & $\mathrm{r}$ \\
\hline SOD3 & $54,69 \pm 163,91$ & \multirow{2}{*}{0,016} & $-0,611$ & $-333,33 \pm 1793,54$ & \multirow{2}{*}{0,712} & $-0,100$ \\
ROS & $24,17 \pm 45,62$ & & & $28,37 \pm 50,26$ & \\
\hline
\end{tabular}

Note: Pearson Correlation test 


\section{Discussion trial}

\subsection{Factors affecting the toxicity in the Bus cabin}

This research was conducted in Biosmart and Safe Bus, which has been designed with a special concept to prevent the risk of exposure to both infectious airborne particles or pollutant fine particles which were toxins in nature. The Biosmart is a concept of forming a more laminar air circulation control system to make the direction of airflow is more vertical. The Biosmart and Safe Bus cabin technology combines HEPA Filter and UV-C lamp technology and covers the entire surface of the bus cabin with Nanosilver. HEPA (High-Efficiency Particulate Air) Filter is a filtering technology that integrates air purification against fine particles whereas HEPA Filter can filter fine particles, smoke, and bacteria measuring up to $0.3 \mu \mathrm{m}$ with a percentage of $99.97 \% .^{(12)}$ Meanwhile, UV-C Lamp is an irradiation method to disinfect and inactivate airborne microorganisms. The radiation wavelength used was $254 \mathrm{~nm}$. The ability of the UV-C lamp to reduce microbial and endotoxin concentrations is up to $99 \%$ without harming the skin of mammals. ${ }^{(13)}$

During the treatment of traveling for approximately 10 hours, several things affect the amount of particles concentration in the cabin space. The cabin temperature is set up at $25^{\circ} \mathrm{C}$ with a Humidity of $66 \%$. The weather conditions during the travel are at the beginning of the year which is in the rainy season. Relatively high rainfall greatly affects the concentration of pollutants in the ambient air environment. The concentration of fine particles such as PM2,5 and PM10 will decrease because they are caught by rainwater particles. ${ }^{(14)}$ The humidity also affects the ability of virus transmission in the air. The relationship between humidity levels and virus inactivation levels in the room is linear with the increase in humidity in the room, which means that the higher the humidity, the greater the virus inactivation. With proper humidity, the virus can be inactivated up to $28 \%$ in 10 minutes. Humidity is an important variable in influencing droplet size changes and the rate of virus inactivation. ${ }^{(15)}$

\subsection{Analysis of Trends, Differences, and Correlation between SOD3 and ROS}

From the results of data analysis, it was found that the trend of changes in SOD3 levels in the treatment group was upward, this is in line with previous research which explained that the anthocyanin content in the Hibiscus rosa Sinensis plant was able to strengthen endogenous antioxidants to increase SOD3 levels. In the control group, the trend of changes in SOD3 levels was upward because it was an adaptive response of cells to acute exposure to an agent lasting less than 24 hours. ${ }^{(16)}$

The SOD3 enzyme is an antioxidant that is widely available in the respiratory tract such as the lungs. ${ }^{(17)}$ It was already well known that SOD3 is a major extracellular enzyme that plays an important role in reducing superoxide ions that have the potentials to cause oxidative damage. Previous studies ${ }^{(18)}$ which assessed the association between exposure of airborne pollutants in the form of PM2.5 to SOD3 levels, showing that PM2.5 and its compound content (nitrate, chloride, and metals) were associated with increased SOD3 levels in acute exposure between 4-8 hours. This will be different if the exposure is less than 1 hour which shows that pollutants can inhibit the activity of antioxidant enzymes. Likewise, chronic exposure which has a duration of more than 48 hours has an inhibitory effect on the activity of antioxidant enzymes. This is consistent with a study of textile factory workers who were exposed to chemicals in the painting process, which found that SOD3 levels decreased when exposed for a longer time (chronic). ${ }^{(19)}$ Furthermore, other studies ${ }^{(20)}$ have shown that short-term exposure to air pollution not only a risk for oxidative damage but also elicits adaptive responses. This condition occurs as an adaptive response by activating a rapid bone marrow response or an early response to cellular signals for gene expression. Metal compounds such as iron-ion transition, titanium, zinc, sodium, aluminum, magnesium, and selenium contained in air pollution were able to induce the production of ROS by cells and trigger cardiovascular injury when inhaled through the respiratory tract. ${ }^{(21)}$

In this study, ROS levels showed a significant increase in the medical masks group but not in NEHRS herbal masks. Previous study reported that NEHRS herbal masks significantly reduced ROS levels in textile industry workers. ${ }^{(22)}$ This shows that NEHRS herbal masks are better than medical masks to prevent the airborne exposure of pollutants that will increase the levels of ROS in cells. ROS compounds act as an initial signal for activation of the natural immune system, wherein conditions such as viral infection, the ROS production process becomes the initial pathway for IFN-Y secretion which plays an important role in fighting viral infections such as respiratory viruses in nasal epithelium cells. From the production, ROS is mainly produced through enzymatic reactions mediated by the enzyme Nicotinamide adenine dinucleotide phosphate-reduced oxidase (Nox). ${ }^{(23)}$ From this study, the results showed that the difference in ROS levels was significantly based on the seating position, especially on the rear position. This shows that the level of exposure in the bus cabin is more dominant in the rear position. This is related to the position of the air ventilation system in the cabin which is in the middle. Previous research examining the transmission of infectious airborne particles in bus cabins has shown that the distance of passengers to the air ventilation system will influence the risk of infectious airborne particles exposure. ${ }^{(24,25)}$ 
The herbal masks that were tested contained the extracts from the Nephrolepis exaltata plant, found that the herbal masks were able to absorb and neutralize VOCs (Volatile Organic Compound). This type of plant can absorb pollutant gas compounds such as formaldehyde, benzene, toluene, and xylene. After being developed with a combination of Hibiscus Rosa Sinensis and tested on online motorcycle taxi riders, it showed the ability to absorb formaldehyde reached $77 \%$ and antioxidant content which has potential as an antimicrobial, anti-inflammatory, and immunoprotective within the respiratory tract. The NEHRS herbal mask design consists of 3 layers and is made with a density of $0.7-1.0 \mu \mathrm{m}$ which is better than the medical mask $(3$ $\mu \mathrm{m})$. ${ }^{(22)}$

There is still a limitation to this study, including no environmental measurement of the levels of pathogenic compounds has done, both for infectious airborne particles nor pollutant particles, which can affect the levels of ROS and SOD3 compounds. In addition, it is necessary to further research the comparisons on public buses, to analyze the effectiveness of the Biosmart and Safe Bus concepts. This study is expected to be scientific reading and information to researcher, government, and public society related to BioSmart and Safe Bus.

\section{Conclusion}

The ROS level of Biosmart and Safe Bus passengers who use Herbal Masks are different from those using regular medical masks with lower levels. The SOD3 level of Biosmart and Safe bus passengers who use herbal masks are different from those using regular medical masks with a higher level although it is not statistically significant.

\section{Acknowledgment}

Thanks to CV Karoseri Laksana and PO Sumber Alam as the bus provider.

\section{References}

1) Troko J, Myles P, Gibson J, Hashim A, Enstone J, Kingdon S, et al. Is public transport a risk factor for acute respiratory infection? BMC Infectious Diseases. 2011;11(1). Available from: https://dx.doi.org/10.1186/1471-2334-11-16.

2) Lindsley WG, Blachere FM, McClelland TL, Neu DT, Mnatsakanova A, Martin SB, et al. Efficacy of an ambulance ventilation system in reducing EMS worker exposure to airborne particles from a patient cough aerosol simulator. Journal of Occupational and Environmental Hygiene. 2019;16(12):804-816. Available from: https://dx.doi.org/10.1080/15459624.2019.1674858.

3) Kolluru SSR, Patra AK, Sahu SP. A comparison of personal exposure to air pollutants in different travel modes on national highways in India. Science of The Total Environment. 2018;619:155-164. Available from: https://dx.doi.org/10.1016/j.scitotenv.2017.11.086.

4) Casola A. Respiratory Viral Infections and Subversion of Cellular Antioxidant Defenses. Journal of Pharmacogenomics \& Pharmacoproteomics. 2014;05(04):141. Available from: https://dx.doi.org/10.4172/2153-0645.1000141.

5) Karoseri Laksana Produksi Bus yang Terapkan Kursi Penumpang Berjarak. 2020. Available from: https://regional.kompas.com/read/2020/07/08/ 13583871/karoseri-laksana-produksi-bus-yang-terapkan-kursi-penumpang-berjarak?page=all.

6) Dzisi EKJ, Dei OA. Adherence to social distancing and wearing of masks within public transportation during the COVID 19 pandemic. Transportation Research Interdisciplinary Perspectives. 2020;7(100191):1-6. Available from: https://dx.doi.org/10.1016/j.trip.2020.100191.

7) Setiyo M, Waluyo B. Captain Seat: Smart Solution for Physical Distancing on Buses During the Covid-19 Pandemic. Automotive Experiences. 2020;4(1):14. Available from: https://dx.doi.org/10.31603/ae.4383.

8) Cherrie JW, Apsley A, Cowie H, Steinle S, Mueller W, Lin C, et al. Effectiveness of face masks used to protect Beijing residents against particulate air pollution. Occupational and Environmental Medicine. 2018;75(6):446-452. Available from: https://dx.doi.org/10.1136/oemed-2017-104765.

9) Prasetyo A, Adi AR, Tsuroya DA, Pawitra IM, Saraswati I, Nur FK. Nephrolepis exaltata Herbal Mask Increases Nasal IgA Levels and Pulmonary Function in Textile Factory Workers. Advances in preventive medicine. 2019;2019(5687135). Available from: https://www.hindawi.com/journals/apm/ 2019/5687135/.

10) Gauthaman KK, Saleem MT, Thanislas PT, Prabhu VV, Krishnamoorthy KK, Devaraj NS, et al. Cardioprotective effect of the Hibiscus rosa sinensis flowers in an oxidative stress model of myocardial ischemic reperfusion injury in rat. BMC Complementary and Alternative Medicine. 2006;6(1):1-8. Available from: https://dx.doi.org/10.1186/1472-6882-6-32.

11) Adar SD, Adamkiewicz G, Gold DR, Schwartz J, Coull BA, Suh H. Ambient and Microenvironmental Particles and Exhaled Nitric Oxide Before and After a Group Bus Trip. Environmental Health Perspectives. 2007;115(4):507-512. Available from: https://dx.doi.org/10.1289/ehp.9386.

12) Liu G, Xiao M, Zhang X, Gal C, Chen X, Liu L, et al. A review of air filtration technologies for sustainable and healthy building ventilation. Sustainable Cities and Society. 2017;32:375-396. Available from: https://dx.doi.org/10.1016/j.scs.2017.04.011.

13) Memarzadeh F. A Review of Recent Evidence for Utilizing Ultraviolet Irradiation Technology to Disinfect Both Indoor Air and Surfaces. Applied Biosafety. 2021;26(1):52-56. Available from: https://dx.doi.org/10.1089/apb.20.0056.

14) Ahmad EF, Santoso M. Analisis Karaterisasi Konsentrasi dan Komposisi Partikulat Udara (Studi Case : Surabaya). Jurnal Kimia VALENSI. 2016;0(0):97103. Available from: https://dx.doi.org/10.15408/jkv.v0i0.3602.

15) Yang W, Marr LC. Dynamics of Airborne Influenza A Viruses Indoors and Dependence on Humidity. PLoS ONE. 2011;6(6):e21481. Available from: https://dx.doi.org/10.1371/journal.pone.0021481.

16) Hatzis C, Godleski JJ, González-Flecha B, Wolfson JM, Koutrakis P. Ambient Particulate Matter Exhibits Direct Inhibitory Effects on Oxidative Stress Enzymes. Environmental Science \& Technology. 2006;40(8):2805-2811. Available from: https://dx.doi.org/10.1021/es0518732.

17) Kobylecki CJ, Afzal S, Nordestgaard BG. Does SOD3 R213G Homozygosity Influence Morbidity, Mortality, and Lung Function in the General Population? Antioxidants \& Redox Signaling. 2016;24(15):884-891. Available from: https://dx.doi.org/10.1089/ars.2016.6629. 
18) Wu S, Wang B, Yang D, Wei H, Li H, Pan L, et al. Ambient particulate air pollution and circulating antioxidant enzymes: A repeated-measure study in healthy adults in Beijing, China. Environmental Pollution. 2016;208:16-24. Available from: https://dx.doi.org/10.1016/j.envpol.2015.06.002.

19) Prasetyo A, Ariani R, Antari AL, Sadhana U, Miranti IP, Kristina TN. Nephrolepis exaltata - Hibiscus rosa-sinensis combination herbal mask decreases levels of reactive oxygen species in nasal wash. Universa Medicina. 2020;39(3):184-191. Available from: https://dx.doi.org/10.18051/univmed.2020.v39. 184-191.

20) Churg A, Xie C, Wang X, Vincent R, Wang RD. Air pollution particles activate NF- $\kappa$ B on contact with airway epithelial cell surfaces. Toxicology and Applied Pharmacology. 2005;208(1):37-45. Available from: https://dx.doi.org/10.1016/j.taap.2005.01.013.

21) Pietro AD, Visalli G, Munaò F, Baluce B, Maestra SL, Primerano P, et al. Oxidative damage in human epithelial alveolar cells exposed in vitro to oil fly ash transition metals. International Journal of Hygiene and Environmental Health. 2009;212(2):196-208. Available from: https://dx.doi.org/10.1016/j.ijheh. 2008.05.005.

22) Prasetyo A, Sabila AA, Dairiyanti A, Aufa MH, Antari AL, Sadhana U, et al. Combination of Nephrolepis Exaltata - Hibiscus Rosa Sinensis Herbal Mask Protect The Sinonasal Immune System and Increase Lung Function of Motorcycle Taxi Drivers. 2020. Available from: https://doi.org/10.21203/rs.3.rs$113277 / \mathrm{v} 1$.

23) Kim HJ, Kim CH, Ryu JH, Kim MJ, Park CY, Lee JM, et al. Reactive Oxygen Species Induce Antiviral Innate Immune Response through IFN$\lambda$ Regulation in Human Nasal Epithelial Cells. American Journal of Respiratory Cell and Molecular Biology. 2013;49(5):855-865. Available from: https://dx.doi.org/10.1165/rcmb.2013-0003oc.

24) Zhu S, Srebric J, Spengler JD, Demokritou P. An advanced numerical model for the assessment of airborne transmission of influenza in bus microenvironments. Building and Environment. 2012;47:67-75. Available from: https://dx.doi.org/10.1016/j.buildenv.2011.05.003.

25) Hong Z, Guo Z, Zhang R, Xu J, Dong W, Zhuang G, et al. Airborne Fine Particulate Matter Induces Oxidative Stress and Inflammation in Human Nasal Epithelial Cells. The Tohoku Journal of Experimental Medicine. 2016;239(2):117-125. Available from: https://dx.doi.org/10.1620/tjem.239.117. 